Jurnal Ekonomi dan Industri

e-ISSN : 2656-3169

Volume 20, No. 3, September-Desember 2019

p-ISSN : 0853-5248

\title{
PENGARUH KUALITAS LAYANAN DAN KEPUASAN PELANGGAN TERHADAP LOYALITAS PELANGGAN PT. ASTRA HONDA MOTOR NAROGONG BEKASI.
}

\author{
M. Irawan Noor *) \\ *) Dosen Program Studi Manajemen FE UNKRIS \\ Alamat: Kampus UNKRIS, Jatiwaringin Jakarta Timur \\ Email : iwandahlia58@gmail.com
}

\begin{abstract}
The increasing demand for two-wheeled motorized vehicles, is an opportunity that continues to be considered to win the existing market competition. Customer loyalty is the key to winning an automotive competition. This study aims to analyze the effect of service quality and customer satisfaction simultaneously or partially on customer loyalty of PT. Astra Honda Motor Narogong Bekasi. This study involved 84 respondents. The results showed that service quality and customer satisfaction both simultaneously and partially on customer loyalty.
\end{abstract}

Keywords: Quality service, customer satisfaction, customer loyalty

\section{PENDAHULUAN}

Meningkatnya permintaan kendaraan bermotor khususnya kendaraan roda dua, menjadi dua sisi yang terus dipertimbangkan dalam memenangkan kompetisi pasar yang ada. Disatu sisi peluang dapat diraih dengan memenuhi kebutuhan yang dimiliki oleh pelanggan, disisi lain konsep pemenuhan kebutuhan pelanggan memiliki banyak sekali yang harus diprioritaskan, dan diupayakan khususnya pada berbagai perubahan layanan yang pada akhirnya akan berdampak pada keberlangsungan hidup perusahaan yang diukur melalui penjualan dalam upaya memenangkan pangsa pasarnya. Pentingnya peningkatan kualitas layanan tidak hanya berdampak bagi kepuasan pelanggan melainkan juga berdampak pada loyalitas pelanggan. Penelitian ini bertujuan untuk menganalisis pengaruh kualitas layanan dan kepuasan pelanggan secara simultan maupun parsial terhadap loyalitas pelanggan PT. Astra Honda Motor Narogong Bekasi.

\section{LANDASAN TEORI}

\section{Loyalitas Pelanggan}

Secara harfiah loyal berarti setia, atau loyalitas dapat diartikan sebagai suatu kesetiaan. Kesetiaan ini diambil tanpa adanya paksaan, tetapi timbul dari kesadaran sendiri pada masa lalu. Usaha yang dilakukan untuk menciptakan kepuasan pelanggan lebih cenderung mempengaruhi sikap pelanggan. Sedangkan konsep loyalitas pelanggan lebih menerangkan kepada perilaku pembelinya. Menurut Rangkuti (2002), "Loyalitas pelanggan adalah kesetiaan pelanggan terhadap perusahaan, merek maupun produk. Sutisna (2003) mendefinisikan loyalitas adalah sikap menyenangi terhadap suatu merek 
yang dipresentasikan dalam pembelian yang konsisten terhadap merek itu sepanjang waktu.

Terdapat beberapa karakteristik loyalitas pelanggan menurut Griffin (2005) antara lain yaitu: 1). Melakukan pembelian ulang secara teratur. Pelanggan melakukan pembelian secara continue pada suatu produk tertentu. Contoh: pencipta motor Harley Davidson akan membeli motor Harley baru jika ada model Harley Davidson yang terbaru, bahkan tidak hanya membeli tetapi mereka juga mengeluarkan uang tambahan untuk mengubahnya sesuai dengan keinginan mereka. 2). Membeli antarlini produk dan jasa. Pelanggan tidak hanya membeli jasa dan produk utama tetapi pelanggan juga membeli lini produk dan jasa dari perusahaan yang sama. Contoh: pelanggan tidak hanya membeli motor Harley davidson saja, tetapi pelanggan juga membeli aksesoris dari Harley Davidson untuk mempercantik dirinya. 3). Mereferensikan kepada orang lain. Dimana pelanggan melakukan komunikasi dari mulut ke mulut (word of mouth) berkenan dengan produk tersebut. Contoh: seorang pelanggan Harley Davidson yang sudah lama memakai motor tersebut, menceritakan tentang kehebatan dan keunggulan dari motor tersebut, kemudian setelah itu temannya tertarik membeli motor Harley Davidson karena mendengar cerita tersebut. 4). Menunjukkan kekebalan terhadap tarikan dari pesaing. Konsumen menolak untuk menggunakan produk atau jasa alternatif yang ditawarkan oleh pesaing. Contoh: para pecinta motor Harley Davidson menolak untuk menggunakan motor lain, bahkan mereka juga cenderung menolak untuk mengetahui jenis-jenis motor lainnya.

Hidayat (2009) mengemukakan bahwa loyalitas pelanggan merupakan komitmen seorang pelanggan terhadap suatu pasar berdasarkan sikap positif dan tercermin dalam pembelian ulang secara konsisten. Indikator dari loyalitas pelanggan tersebut adalah: 1). Trust merupakan tanggapan kepercayaan konsumen terhadap pasar. 2). Emotion commitment merupakan komitmen psikologi konsumen terhadap pasar. 3). Switching cost merupakan tanggapan konsumen tentang beban yang diterima ketika terjadi perubahan. 4). Word of mouth merupakan perilaku publisitas yang dilakukan konsumen terhadap pasar. 5). Cooperation merupakan perilaku konsumen yang menunjukan sikap yang bekerja sama dengan pasar.

\section{Kualitas Layanan}

Kualitas pelayanan jasa menurut Tjiptono (2011) diartikan sebagai tingkat keunggulan yang diharapkan dan pengendalian atas tingkat keunggulan tersebut untuk memenuhi keinginan pelanggan. Lebih jauh Lewis dan Booms dikutip oleh Tjiptono (2011) kualitas layanan merupakan ukuran seberapa bagus tingkat layanan yang diberikan mampu sesuai dengan ekspektasi pelanggan.

Tjiptono (2011) enam prinsip utama tersebut antara lain yaitu: 1). Kepemimpinan. Strategi kualitas perusahaan harus merupakan inisiatif dan komitmen dari manajemen puncak. Manajemen puncak harus memimpin perusahaan untuk meningkatkan kinerja kualitasnya. Tanpa adanya kepemimpinan dari manajemen puncak, maka usaha untuk meningkatkan kualitas hanya berdampak kecil terhadap perusahaan. 2). Pendidikan. Semua anggota dalam perusahaan mulai dari manajer puncak sampai karyawan operasional harus memperoleh pendidikan mengenai kualitas. 3). Perencanaan. Proses perencanaan strategis harus mencakup pengukuran dan tujuan kualitas yang dipergunakan dalam mengarahkan perusahaan untuk mencapai visinya. 4). Review. Proses review merupakan satu-satunya alat yang paling efektif bagi manajemen puncak untuk mengubah perilaku organisasional. Proses ini merupakan suatu mekanisme yang menjamin adanya perhatian yang konsisten dan berkesinambungan untuk mencapai tujuan kualitas. 5). Komunikasi. Impementasi strategi kualitas dalam sebuah perusahaan dipengaruhi oleh proses komunikasi dalam 
perusahaan. 6). Penghargaan dan pengakuan (total human reward). Penghargaan dan pengakuan merupakan aspek yang penting dalam implementasi strategi kualitas. Setiap karyawan yang berprestasi baik perlu diberi penghargaan dan prestasinya pun diakui. Dengan demikian dapat meningkatkan motivasi, moral kerja, rasa bangga dan rasa kepemilikan setiap orang dalam perusahaan, yang pada gilirannya dapat memberikan kontribusi besar bagi perusahaan dan bagi pelanggan yang dilayani. Lebih jauh Tjiptono (2011) pengukuran yang dapat digunakan dalam mengukur kualitas pelayanan jasa antara lain: 1). Keandalan (reliability) yaitu kemampuan memberikan pelayanan yang dijanjikan dengan segera, akurat dan memuaskan. 2). Daya tanggap (responsiveness) yaitu keinginan para staf untuk membantu para pelanggan dan memberikan pelayanan dengan tanggap. 3). Jaminan (asurance) mecakup pengetahuan, kemampuan, kesopanan, dan sifat dapat dipercaya yang dimiliki para staf bebas dari bahaya, risiko atau keraguan. 4). Empati (empathy) meliputi kemudahan dalam melakukan hubungan komunikasi yang baik, perhatian pribadi, dan memahami kebutuhan para pelanggan. 5). Bukti langsung (tangibles) meliputi fasilitas fisik, perlengkapan, karyawan, serta sarana komunikasi.

\section{Kepuasan Pelanggan}

Wilkie yang dikutip Tjiptono (2008) mendefinisikan kepuasan pelanggan sebagai suatu tanggapan emosional pada evaluasi terhadap pengalaman konsumsi suatu produk atau jasa. Kemudian Engel, et al yang dikutip Tjiptono (2008) menyatakan bahwa kepuasan pelanggan merupakan evaluasi purna beli dimana alternatif yang dipilih sekurang-kurangnya sama atau melampaui harapan pelanggan, sedangkan ketidakpuasan muncul apabila hasil (outcome) tidak memenuhi harapan.

Kotler yang dialihbahasakan Molan (2005) membagi kepuasan pelanggan dalam 5 level, mulai dari tingkat dimana pelanggan merasakan ketidakpuasan hingga tingkat dimana pelanggan merasakan kepuasan yang sangat. Pada level satu, para pelanggan cenderung menjauhi perusahaan dan menyebarkan cerita jelek tentang perusahaan tersebut. Pada level dua sampai empat, pelanggan merasa agak puas tetapi merasa mudah untuk beralih ketika tawaran yang lebih baik muncul. Pada level lima, pelanggan merasakan sangat puas dan cenderung membeli ulang dan bahkan menyampaikan cerita pujian tentang perusahaan.

Indikator yang digunakan dalam mengukur kepuasan pelanggan menurut Wilkie (2006) yaitu sebagai berikut: 1). Harapan (Expectations). Harapan pelanggan terhadap suatu barang atau jasa telah dibentuk sebelum pelanggan membeli barang atau jasa tersebut. Pada saat proses pembelian dilakukan, pelanggan berharap bahwa barang atau jasa yang mereka terima sesuai dengan harapan, keinginan, dan keyakinan mereka. Faktor -faktor yang mempengaruhi persepsi dan harapan pelanggan adalah sebagai berikut : a). Kebutuhan dan keinginan yang berkaitan dengan hal-hal yang dirasakan pelanggan ketika sedang mencoba melakukan transaksi dengan produsen produk (perusahaan). b). Pengalaman masa lalu ketika mengkonsumsi produk dari perusahaan maupun pesaingpesaingnya. c). Pengalaman dari teman-teman. d). Komunikasi melalui iklan dan pemasaran. 2). Kinerja (Performance). Performance merupakan pengalaman pelanggan terhadap kinerja aktual barang atau jasa ketika digunakan tanpa dipengaruhi oleh harapan mereka. Selama mengkonsumsi suatu produk atau jasa, pelanggan menyadari kegunaan produk aktual dan menerima kinerja produk tersebut sebagai dimensi yang penting bagi pelanggan. 3). Perbandingan (Comparison). Setelah mengkonsumsi barang atau jasa maka pelanggan akan membandingkan harapan terhadap kinerja barang atau jasa sebelum membeli dengan kinerja aktual barang atau jasa tersebut. 4). Confirmation atau disconfirmation. Harapan pelanggan dipengaruhi oleh pengalaman pelanggan terhadap 
penggunaan merek dari barang atau jasa yang berbeda atau dari pengalaman orang lain. Melalui penggunaan merek lain dan komunikasi dari perusahaan serta orang lain, pelanggan membandingkan harapan kinerja barang atau jasa yang dibeli dengan kinerja aktual barang atau jasa tersebut. Confirmation terjadi ketika harapan sesuai dengan kinerja aktual produk. Disconfirmation terjadi ketika harapan lebih tinggi atau lebih rendah dari kinerja aktual produk. Pelanggan akan merasa puas ketika terjadi confirmation dan disconfirmation yaitu ketika harapan melebihi kinerja aktual barang atau jasa. 5). Ketidaksesuaian (Discrepancy). Discrepancy mengindikasikan bagaimana perbedaan antara level kinerja dengan harapan. Negatif disconfimations yaitu ketika kinerja aktual berada dibawah level harapan, kesenjangan yang lebih luas lagi akan mengakibatkan tingginya level ketidakpuasan. Sebaliknya positive disconfimations yaitu ketika kinerja aktual berada diatas level harapan. Ketika pelanggan puas, maka pelanggan akan menggunakan barang atau jasa yang sama, dan ketika pelanggan merasa tidak puas maka pelanggan akan menuntut perbaikan atau komplain terhadap perusahaan.

\section{METODE PENELITIAN}

Penelitian ini merupakan penelitian yang menjelaskan hubungan kausalitas antara kualitas pelayanan dan kepuasan pelanggan terhadap loyalitas pelanggan. Data penelitian yang digunakan adalah dengan menggunakan data primer dan data sekunder. Untuk data primer diperoleh menggunakan angket, sedangkan untuk data sekunder dengan menggunakan website yang dimiliki objek penelitian. Responden yang menjadi populasi dalam penelitian ini adalah pelanggan PT. Astra Honda Motor Narogong Bekasi sebanyak 84 responden yang datang pada bulan April 2019. Jumlah sampel penelitian sebanyak 84 orang responden, sampel penelitian diambil menggunakan tehnik sampling jenuh.

\section{HASIL PENELITIAN DAN PEMBAHASAN}

\section{Uji Validitas}

Tabel 1. Hasil Uji Validitas Instrumen Variabel Kualitas Layanan

\begin{tabular}{ccccc}
\hline Variabel & Pertanyaan & R hitung & R tabel & Keterangan \\
\hline & Pertanyaan 1 & 0,937 & 0,220 & Valid \\
& Pertanyaan 2 & 0,919 & 0,220 & Valid \\
& Pertanyaan 3 & 0,904 & 0,220 & Valid \\
& Pertanyaan 4 & 0,915 & 0,220 & Valid \\
Kualitas Layanan & Pertanyaan 5 & 0,900 & 0,220 & Valid \\
$\left(\mathbf{X}_{1}\right)$ & Pertanyaan 6 & 0,962 & 0,220 & Valid \\
& Pertanyaan 7 & 0,914 & 0,220 & Valid \\
& Pertanyaan 8 & 0,953 & 0,220 & Valid \\
& Pertanyaan 9 & 0,952 & 0,220 & Valid \\
& Pertanyaan 10 & 0,879 & 0,220 & Valid \\
\hline
\end{tabular}

Sumber: Data Primer, diolah tahun 2019 
Tabel 2. Hasil Uji Validitas Instrumen Variabel Kepuasan Pelanggan

\begin{tabular}{ccccc}
\hline Variabel & Pertanyaan & R hitung & R tabel & Keterangan \\
\hline & Pertanyaan 1 & 0,947 & 0,220 & Valid \\
& Pertanyaan 2 & 0,881 & 0,220 & Valid \\
& Pertanyaan 3 & 0,957 & 0,220 & Valid \\
& Pertanyaan 4 & 0,932 & 0,220 & Valid \\
Kepuasan Pelanggan & Pertanyaan 5 & 0,938 & 0,220 & Valid \\
$\left(\mathbf{X}_{2}\right)$ & Pertanyaan 6 & 0,918 & 0,220 & Valid \\
& Pertanyaan 7 & 0,959 & 0,220 & Valid \\
& Pertanyaan 8 & 0,963 & 0,220 & Valid \\
& Pertanyaan 9 & 0,968 & 0,220 & Valid \\
& Pertanyaan 10 & 0,901 & 0,220 & Valid \\
\hline
\end{tabular}

Sumber: Data Primer, diolah tahun 2019

Tabel 3. Hasil Uji Validitas Instrumen Variabel Loyalitas Pelanggan

\begin{tabular}{ccccc}
\hline Variabel & Pertanyaan & R hitung & R tabel & Keterangan \\
\hline & Pertanyaan 1 & 0,926 & 0,220 & Valid \\
& Pertanyaan 2 & 0,963 & 0,220 & Valid \\
& Pertanyaan 3 & 0,966 & 0,220 & Valid \\
Loyalitas Pelanggan & Pertanyaan 4 & 0,974 & 0,220 & Valid \\
(Y) & Pertanyaan 5 & 0,961 & 0,220 & Valid \\
& Pertanyaan 6 & 0,931 & 0,220 & Valid \\
& Pertanyaan 7 & 0,952 & 0,220 & Valid \\
& Pertanyaan 8 & 0,940 & 0,220 & Valid \\
& Pertanyaan 9 & 0,968 & 0,220 & Valid \\
& Pertanyaan 10 & 0,950 & 0,220 & Valid \\
\hline
\end{tabular}

Sumber: Data Primer, diolah tahun 2019

Dari Tabel 1, .2, dan 3, dapat dilihat bahwa dari 30 butir pertanyaan variabel yang digunakan (variabel kualitas layanan, kepuasan pelanggan, dan loyalitas pelanggan) hasilnya adalah valid. Adapun kriteria yang digunakan dalam menentukan valid tidaknya pernyataan yang digunakan dalam penelitian ini yaitu menggunakan tingkat kepercayaan $=$ 95 persen (probabilitas atau $\alpha=5 \%$ ), derajat kebebasan $(\mathrm{dk})=84-2=82$, di dapat $\mathrm{r}$ tabel $=$ 0.220. Jika $\mathrm{r}$ hitung lebih besar dari $\mathrm{r}$ tabel dan nilai $\mathrm{r}$ positif, maka butir pernyataan dikatakan valid.

\section{Uji Reliabilitas}

Pada tabel hasil pengujian berikut diketahui bahwa semua variabel mempunyai alpha di atas 0,6 yang berarti bahwa semua variabel dalam penelitian ini dapat diandalkan.

Tabel 4. Hasil Uji Reliabilitas Instrumen Variabel Penelitian

\begin{tabular}{lcc}
\hline \multicolumn{1}{c}{ Variabel } & Cronbach Alpha $(\boldsymbol{\alpha})$ & Keterangan \\
\hline Kualitas layanan $\left(\mathrm{X}_{1}\right)$ & 0,984 & Reliabel \\
Kepuasan pelanggan $\left(\mathrm{X}_{2}\right)$ & 0,987 & Reliabel \\
Loyalitas pelanggan $(\mathrm{Y})$ & 0,991 & Reliabel \\
\hline
\end{tabular}

Sumber: Data Primer, diolah tahun 2019 
Berdasarkan angka-angka reliabilitas cronbach alpha dapat dilihat bahwa seluruh pernyataan yang ada membentuk ukuran yang reliabel yaitu dari variabel kualitas pelayanan, kepuasan pelanggan, dan loyalitas pelanggan membentuk ukuran yang reliabel dari masing-masing dimensi.

\section{Hasil penelitian}

Tabel 5. Pengaruh Kualitas Layanan dan Kepuasan Pelanggan Terhadap Loyalitas Pelanggan

\begin{tabular}{ccccccc}
\hline Hubungan & \multicolumn{5}{c}{ Parameter } \\
\cline { 2 - 6 } Variabel & Mult. R & R Square & Konstanta & Koef. B & Sig. & $\boldsymbol{\alpha}$ \\
\hline $\begin{array}{c}\text { Kualitas } \\
\text { Layanan }\end{array}$ & 0.992 & 0.984 & 1.905 & 0.665 & 0.000 & \\
$\begin{array}{c}\text { Kepuasan } \\
\text { Pelanggan }\end{array}$ & & & & 0.378 & 0.000 & 0.05 \\
\hline
\end{tabular}

\section{Pengujian Signifikansi}

F hitung $>\mathrm{F}$ tabel $=24.030>3.110$

Hasil $\mathrm{F}$ hitung sebesar 24.030 jika dibandingkan dengan $\mathrm{F}$ tabel (apha $=0,05$ $\mathrm{DF}=2 ; 82$ ), maka nilai $\mathrm{F}$ tabel sebesar 3.11. Nilai $\mathrm{F}$ hitung lebih besar dari F tabel. Hal ini mencerminkan bahwa secara bersama-sama ada pengaruh kualitas layanan dan kepuasan pelanggan terhadap loyalitas pelanggan.

Nilai koefisien determinasi $\left(\mathrm{R}^{2}\right)$ sebesar 0,984 atau 98.4 persen. Nilai ini menunjukkan bahwa pembentukan tinggi rendahnya loyalitas pelanggan disumbangkan oleh kualitas layanan dan kepuasan pelanggan sebesar 98.4 persen, sisanya sebesar 1.6 persen disumbangkan oleh variabel lain diluar variabel kualitas layanan dan kepuasan pelanggan.

Persamaan regresi $\mathrm{Y}=1,905+0,665 \mathrm{X}_{1}+0,378 \mathrm{X}_{2}$.

Dari persamaan regresi yang disusun dapat dilihat bahwa nilai koefisien regresi kualitas layanan sebesar 0,665 nilai ini mengartikan bahwa peningkatan kualitas layanan memberikan dampak bagi loyalitas pelanggan sebesar 0.665. Nilai koefisien regresi kepuasan pelanggan yaitu sebesar 0.378 , nilai ini mengartikan bahwa kepuasan pelanggan memberikan dampak bagi loyalitas pelanggan sebesar 0.378. Berdasarkan analisis yang telah dilakukan dapat disimpulkan bahwa hipotesis pertama penelitian yaitu kualitas layanan dan kepuasan pelanggan berpengaruh secara simultan terhadap loyalitas pelanggan PT. Astra Honda Motor Narogong Bekasi dapat diterima dan dibuktikan. Dengan dibuktikannya hipotesis ini sejalan dengan hasil penelitian Tanisah dan Maftuhah (2015) dan Saleem dan Raja (2014).

Tabel 6. Pengaruh Kualitas Layanan Terhadap Loyalitas Pelanggan

\begin{tabular}{ccccccc}
\hline Hubungan & \multicolumn{6}{c}{ Parameter } \\
\cline { 2 - 6 } Variabel & Mult. R & R Square & Konstanta & Koef. B & Sig. & $\boldsymbol{\alpha}$ \\
\hline $\begin{array}{l}\text { Kualitas } \\
\text { Layanan }\end{array}$ & 0.989 & 0.978 & 3.202 & 1.065 & 0.000 & 0.05 \\
\hline $\begin{array}{l}\text { Pengujian Signifikansi } \\
\text { t hitung }>\text { t tabel }=6.566>1.671\end{array}$ & & & & \\
\hline
\end{tabular}


Nilai koefisien determinasi $\left(\mathrm{R}^{2}\right)$ sebesar 0,978 atau 97.8 persen. Nilai ini menunjukkan bahwa pembentukan loyalitas pelanggan disumbangkan oleh kualitas layanan sebesar 97.8 persen, sisanya sebesar 2.2 persen disumbangkan oleh variabel lain diluar kualitas layanan.

$$
\text { Persaman regresi } \mathrm{Y}=3.202+1.065\left(\mathrm{X}_{1}\right)
$$

Dari persamaan regresi yang disusun dapat dilihat bahwa nilai koefisien regresi kualitas layanan sebesar 1,065 nilai ini mengartikan bahwa peningkatan kualitas layanan memberikan dampak bagi loyalitas pelanggan sebesar 0.665. Berdasarkan analisis yang telah dilakukan dapat disimpulkan hipotesis kedua penelitian ini yaitu kualitas layanan berpengaruh secara parsial terhadap loyalitas pelanggan PT. Astra Honda Motor Narogong Bekasi dapat dibuktikan dan diterima. Pernyataan ini mendukung hasil penelitian yang dilakukan oleh Marina, et al (2014) yang menyatakan bahwa kualitas pelayanan berpengaruh terhadap loyalitas pelanggan.

Tabel 7. Pengaruh Kepuasan Pelanggan Terhadap Loyalitas Pelanggan

\begin{tabular}{ccccccc}
\hline Hubungan & \multicolumn{6}{c}{ Parameter } \\
\cline { 2 - 6 } Variabel & Mult. R & R Square & Konstanta & Koef. B & Sig. & $\boldsymbol{\alpha}$ \\
\hline $\begin{array}{c}\text { Kepuasan } \\
\text { Pelanggan }\end{array}$ & 0.984 & 0.969 & 1.248 & 0.984 & 0.000 & 0.05 \\
\hline
\end{tabular}

Pengujian Signifikansi

$\mathrm{t}$ hitung $>\mathrm{t}$ tabel $=5.546>1.671$

Nilai koefisien determinasi $\left(\mathrm{R}^{2}\right)$ sebesar 0,984 atau 98.4 persen. Nilai ini menunjukkan bahwa pembentukan loyalitas pelanggan disumbangkan oleh kepuasan pelangggan sebesar 98.4 persen, sisanya sebesar 1.6 persen disumbangkan oleh variabel lain diluar kepuasan pelanggan.

\section{Persaman regresi $\mathrm{Y}=1.248+0.984\left(\mathrm{X}_{2}\right)$}

Dari persamaan regresi yang disusun dapat dilihat bahwa nilai koefisien regresi kepuasan pelanggan sebesar 0,984 nilai ini mengartikan bahwa peningkatan kepuasan pelanggan memberikan dampak bagi loyalitas pelanggan sebesar 0.984. Berdasarkan analisis yang telah dilakukan dapat disimpulkan hipotesis kedua penelitian ini yaitu kepuasan pelanggan berpengaruh secara parsial terhadap loyalitas pelanggan PT. Astra Honda Motor Narogong Bekasi dapat dibuktikan dan diterima. Pernyataan ini mendukung hasil penelitian yang dilakukan oleh Putra, et al (2017) yang menyatakan kualitas pelayanan berpengaruh terhadap loyalitas konsumen.

\section{Pembahasan}

Pengaruh kualitas layanan terhadap loyalitas pelanggan mengartikan bahwa setiap kenaikan kualitas layanan memberikan dampak bagi loyalitas pelanggan. Implementasi dari pernyataan ini dapat dilakukan dengan memperhatikan indikator kualitas pelayanan antara lain keandalan (reliability) dan bukti langsung (tangibles). Pada indikator keandalan (reliability) dapat diimplementasikan pada waktu yang dibutuhkan dalam memberikan pelayanan sangat cepat sudah dirasakan oleh pelanggan, serta ketersediaan kelengkapan fasilitas pelayanan sangat membantu karyawan dalam memberikan pelayanan yang cepat sehingga pelanggan merasa puas dan pada akhirnya meningkatkan loyalitas pelanggan. 
Implementasi pada indikator bukti langsung (tangibles) dapat dilakukan dengan menyediakan fasilitas ruang tunggu sangat layak dan nyaman serta memperbanyak ketersediaan jumlah loket dan karyawan sudah sesuai dengan rata-rata pelanggan yang datang akan mendorong peningkatan loyalitas pelanggan. Dengan dibuktikannya kualitas layanan berpengaruh terhadap loyalitas pelanggan maka memperkuat hasil penelitian Sandriana Marina, Andi Darmawati, dan Indra Setiawan (2014).

Pengaruh kepuasan pelanggan terhadap loyalitas pelanggan mengartikan bahwa setiap kenaikan dari kepuasan pelanggan memberikan dampak bagi loyalitas pelanggan. Implementasi dari pernyataan ini dapat dilakukan dengan memperhatikan indikator kepuasan pelanggan antara lain harapan (expectations) dan ketidaksesuaian (discrepancy). Pada indikator harapan (expectations) dapat diimplementasikan pada pemenuhan kualitas layanan yang ditawarkan perusahaan sesuai dengan harapan pelanggan, serta peningkatan pengetahuan karyawan dapat membantu perusahaan dalam memenuhi harapan pelanggan dapat mendorong peningkatan loyalitas pelanggan. Kemudian pada indikator ketidaksesuaian (discrepancy) dapat diimplementasikan pada mendengarkan komplain yang dilakukan pelanggan merupakan evaluasi terhadap layanan yang diberikan serta meningkatkan pengetahuan dan kemampuan karyawan dalam memberikan pelayanan adalah faktor utama dalam memperkecil komplain pelanggan dapat mendorong loyalitas pelanggan. Dengan dibuktikannya kepuasan pelanggan berpengaruh terhadap loyalitas pelanggan maka memperkuat hasil penelitian Hilman Ardianta Putra dan Ngatno (2017).

\section{KESIMPULAN DAN SARAN}

\section{Kesimpulan}

1 Kualitas layanan dan kepuasan pelanggan berpengaruh secara simultan terhadap loyalitas pelanggan PT. Astra Honda Motor Narogong Bekasi dapat diterima dan dibuktikan. Hasil analisis koefisien regresi pada persamaan simultan mengartikan bahwa untuk mendorong loyalitas pelanggan manajemen lebih memprioritaskan pada peningkatan kualitas pelayanan kemudian diikuti oleh pembentukan kepuasan pelanggan. Pernyataan ini mendukung hasil penelitian Tanisah dan Ida Maftuhah (2015) dan Hamad Saleem dan Naintara Sarfraz Raja (2014).

2 Kualitas layanan berpengaruh secara parsial terhadap loyalitas pelanggan PT. Astra Honda Motor Narogong Bekasi dapat dibuktikan dan diterima. Hasil analisis koefisien regresi pada persamaan parsial mengartikan bahwa manajemen perusahaan memperhatikan keandalan (reliability), daya tanggap (responsiveness), jaminan (asurance), empati (empathy), dan bukti langsung (tangibles) maka memberikan dampak positif bagi peningkatan loyalitas pelanggan. Pernyataan ini mendukung hasil penelitian Sandriana Marina, Andi Darmawati, dan Indra Setiawan (2014) yang menyatakan bahwa kualitas pelayanan berpengaruh terhadap loyalitas pelanggan.

3 Kepuasan pelanggan berpengaruh secara parsial terhadap loyalitas pelanggan PT. Astra Honda Motor Narogong Bekasi dapat dibuktikan dan diterima. Hasil analisis koefisien regresi pada persamaan parsial mengartikan bentuk perhatian manajemen pada inovasi terhadap layanan dalam menarik hati pelanggan maupun calon pelanggan berdampak pada loyalitas pelanggan. Pernyataan ini mendukung hasil penelitian Hilman Ardianta Putra dan Ngatno (2017) yang menyatakan kualitas pelayanan berpengaruh terhadap loyalitas konsumen. 


\section{Saran}

1. Hasil analisis menunjukkan bahwa kualitas pelayanan mempengaruhi loyalitas pelanggan PT. Astra Honda Motor Narogong Bekasi. Masukan yang dapat disampaikan yaitu peningkatan kualitas pelayanan yang diimplementasikan pada indikator empati (empathy) yaitu karyawan harus mampu secara cepat dan tanggap dalam memahami kebutuhan pelanggan.

2. Faktor lain yang tidak kalah pentingnya dalam membahas loyalitas pelanggan yaitu kepuasan pelanggan. Dalam memperhatikan kepuasan pelanggan manajemen perusahaan dapat memperhatikan indikator Perbandingan (comparison) yang diimplementasikan pada inovasi terhadap layanan agar menarik hati pelanggan maupun calon pelanggan.

3. Bagi penelitian lain yang ingin mengangkat variabel yang sama hendaknya lebih mengkombinasikan pengukuran-pengukuran maupun dimensi yang melekat pada variabel yang telah dikaji dalam penelitian ini. Jika hal ini dilakukan diharapkan dapat lebih menyempurnakan kualitas dari hasil penelitian ini, karena penulis sangat menyadari bahwa penelitian yang telah disusun masih jauh dari kesempurnaan baik dalam aspek penentuan jumlah pengambilan sampel maupun indikator yang digunakan.

\section{DAFTAR PUSTAKA}

Alimul Hidayat. Aziz., 2009. Metode Penelitian Keperawatan dan Tekhnik Analisis Data. Salemba Medika. Jakarta.

Benyamin Molan., 2005. Manajemen Pemasaran. Penyunting Bambang Sarwiji. Jilid Satu Edisi Kesebelas. Indeks. Jakarta.

Fandy, Tjiptono., 2011.Service Management Mewujudkan Layanan Prima. Edisi 2. Andi. Yogyakarta.

Fandy Tjiptono., 2008, Strategi Pemasaran, Edisi 3, ANDI: Yogyakarta.

Griffin, Jill., 2005. Customer Loyalty: Menumbuhkan \& Mempertahankan Kesetiaan Pelanggan. Erlangga. Jakarta.

Hilman Ardianta Putra dan Ngatno., 2017. Pengaruh Kualitas Pelayanan Terhadap Loyalitas Konsumen Melalui Kepuasan Konsumen Sebagai Variabel Intervening (Studi Kasus Pada Konsumen PT. Lontar Media Digital Printing Semarang). Diponegoro Journal Of Social And Political Tahun 2017, Hal 1-8.

Rangkuti, Freddy., 2002. Measuring Customer Satisfaction, Penerbit PT Gramedia Pustaka Utama, Jakarta.

Saleem, Hamad and Naintara Sarfraz Raja. 2014. The Impact of Service Quality on Customer Seaticfaction, Customer Loyalty and Brand Image: Evidence From Hotel Industry of Pakistan. Journal of Scientific Research, XIX (5): 706-711.

Sandriana Marina, Andi Darmawati dan Indra Setiawan dengan judul "Pengaruh Kualitas pelayanan terhadap Loyalitas pelanggan pada Perusahaan Penerbangan Full Service Airlines". Jurnal Manajemen Transportasi \& Logistik (JMTransLog), Volume 01, No. O2, Juli 2014, ISSN: 2355-4721

Sugiyono. 2012. Metode Penelitian Kuantitatif Kualitatif dan R\&D. Alfabeta. Bandung.

Sutisna. 2003., Perilaku Konsumen dan Komunikasi Pemasaran. PT. Remaja Rosdakarya. Bandung. 
Tanisah \& Ida Maftuhah. 2015. The Effect Of Service Quality, Customer Satisfaction, Trust, And Perceived Value Towards Customer Loyalty, Jurnal Dinamika Manajemen $\quad$ Vol. $\quad 6 \quad$ No. $\quad 1, \quad$ dalam https://journal.unnes.ac.id/nju/index.php/jdm/article/view/4296, diakses tanggal 10 April 2019.

Wilkie, W.L. 2006. Customer Behavior, Edisi Kedua. John Wiley \& Sons, Inc. New York. 